\title{
AC 2012-5106: ON INTEGRATING APPROPRIATE TECHNOLOGY RE- SPONSIVE TO COMMUNITY CAPABILITIES: A CASE STUDY FROM HAITI
}

\author{
Dr. William Joseph Frey, University of Puerto Rico, Mayagez
}

William Frey teaches business, computer, and engineering ethics at the University of Puerto Rico, Mayagez. For several years, he directed the university's Center for Ethics in the Professions. His interests, besides practical and professional ethics, include moral pedagogy and moral psychology. He is active in the Society for Ethics Across the Curriculum and the Association for Practical and Professional Ethics and has presented and participated in workshops at ASEE since 2000. He is also a Co-investigator on the project Graduate Research and Education for Appropriate Technology: Inspiring Direct Engagement and Agency (GREAT IDEA).

\section{Prof. Christopher Papadopoulos, University of Puerto Rico, Mayaguez}

Christopher Papadopoulos is an Assistant Professor in the Department of General Engineering at the University of Puerto Rico, Mayagez (UPRM). He earned B.S. degrees in Civil Engineering and Mathematics from Carnegie Mellon University (1993) and a Ph.D. in Theoretical \& Applied Mechanics at Cornell University (1999). Prior to coming to UPRM, Papadopoulos served on the faculty in the Department of Civil Engineering \& Mechanics at the University of Wisconsin-Milwaukee (UWM).

Papadopoulos has diverse research and teaching interests in structural mechanics, biomechanics, engineering ethics, and engineering education. He is PI of the project Graduate Research and Education for Appropriate Technology: Inspiring Direct Engagement and Agency (GREAT IDEA) that supports and prepares graduate researchers to pursue research and development activities that address issues of developing communities. Papadopoulos is also the Secretary of the ASEE Mechanics Division and serves on numerous committees at UPRM that relate to undergraduate and graduate education.

Marcel J. Castro-Sitiriche, University of Puerto Rico, Mayagez

Marcel J. Castro-Sitiriche is Assistant Professor of Electrical Engineering at the University of Puerto Rico, Mayagez (Recinto Universitario de Mayagez). His research efforts include academic, educational, and service activities. Some of the research areas of interest include appropriate technology, engineering education, power electronics, computational intelligence, electric motor drives, and renewable energy systems. One of the current research projects combine most of the research interests and is based in the concept of appropriate technology. The project title is Graduate Research and Education for Appropriate Technology: Inspiring Direct Engagement and Agency (GREAT IDEA).

Fatima Zevallos, University of Puerto Rico, Mayagez

Fatima Zevallos is a senior in geology at the University of Puerto Rico, Mayagez, where she is also employed as a geophysical data Student Analyst at the Puerto Rico Seismic Network. She is currently employed as an undergraduate Research Assistant with the Graduate Research and Education for Appropriate Technology: Inspiring Direct Engagement and Agency (GREAT IDEA) project. Zevallos is a native of Port au Prince, Haiti, and is fluent in Haitian Creole, French, English, and Spanish. She plans to return back to her hometown to share and apply her scientific knowledge in seismology.

\section{Denisse Echevarria , University of Puerto Rico, Mayagez}

Denisse Echevarria is a junior in mechanical engineering at the University of Puerto Rico, Mayagez. Echevarria is currently employed as an Undergraduate Research Assistant with the Graduate Research and Education for Appropriate Technology: Inspiring Direct Engagement and Agency (GREAT IDEA) project. She is generally interested in how engineers can make a difference to cause positive social change, and she is particularly interested in studying mechanical aspects of wind turbine construction.

(C)American Society for Engineering Education, 2012 


\section{On Integrating Appropriate Technology Responsive to Community Capabilities: A Case Study from Haiti}

\section{Introduction}

During the past decades, efforts have been made to apply engineering to address problems of developing countries. Many of these are identified with groups such as Engineers Without Borders, Engineers for a Sustainable World and the IEEE Society for Social Implications of Technology.

Recent work has examined this "engineering to help" movement, and designations such as "peace engineering"" and "humanitarian engineering", now represent recognized fields of inquiry and practice. Several authors have framed these efforts within a context of engineering ethics, and within this framework, they have worked to incorporate perspectives of social justice $3,4,5$

One recurrent theme from these commentaries is the requirement to involve local communities, not as passive recipients, but as true partners at all stages of the development process ${ }^{3}$. When genuinely undertaken, this act of partnering has both moral and practical implications. For example, recognizing and incorporating a community's essential capabilities while developing a project conveys respect and leads to appropriate technical specifications that ultimately result in a system that will be accepted and sustained. And, as many have observed, technology projects that insist on paternalistic, top-down implementations have a long history of failure. This exposes the fallacy of viewing these projects as "expert"-driven technical fixes while underscoring the importance of working within the underlying socio-technical system. For these reasons, we extend appropriate technology to cover the design and development of useful technologies that properly partner with the local community.

This paper will explore appropriate technology in the context of our work in the small, rural community of Duchity, Haiti that began in November 2010. We begin with a conceptual map tracing the relations and distinctions between appropriate technology, socio-technical systems, humanitarian engineering, and the Capabilities Approach. Each of these has been closely examined in book-length studies. Thus, our treatment here will necessarily be brief but essential to avoid the mistakes of paternalism outlined so well in Easterly's The White Man's Burden.

Next, we examine how two issues central to RCR (Responsible Conduct of Research), avoiding paternalism and facilitating informed consent, transfer to this context of appropriate technology, but with necessary modification so that they shed light on sustainable technological projects in developing communities. The localization implied in Easterly's notion of "seekers" provides an effective antidote to the disastrous paternalism brought about by the top-down, one-size-fits-all approach of the "planners" Outlining a seekers perspective that avoids paternalism leads to an appropriate interpretation of informed consent from all participants.

Moving from this, we summarize the preliminary results of a survey conducted in Duchity, Haiti in October 2011 that was intended to lay bare some of the capabilities of the community and how these could be realized or frustrated by means of a proposed hydroelectric project. The goal here 
is to outline how engineers can serve, not only as technical advisors, but also as facilitators of a small and local community's dialogic exploration of its own philosophy of technology. We conclude with a discussion of what we can learn working in Haiti that can help our students imagine and construct different career paths that employ engineering skills for community development and appropriate technology. Through our project, we hope to show how engineers can gain skills to work as true enablers who facilitate the conversion of local capabilities into realized functions.

\section{Basic Concepts}

Appropriate Technology. The term "appropriate technology" comes from economist E. F. Schumacher and plays a prominent role in his book, Small Is Beautiful. Here, appropriate technology is used interchangeably with intermediate technology, that is, technology "intermediate" between the "indigenous technology of developing countries" and developed country or "high capital intensive technology"7 . Intermediate technology is appropriate in the sense that it mitigates the harmful social consequences of moving too quickly from indigenous, labor intensive technology to high capital intensive technology. Technology appropriate to orderly, sustainable or even humane development (a) gives "special consideration...to context of use, including environmental, ethical, cultural, social, political, and economical aspects" ;(b) seeks simplicity (as opposed to what Langdon Winner ${ }^{9}$ terms manifest and latent complexity); (c) chooses decentralization over authoritarian centralization; (d) employs labor intensive as opposed to capital intensive strategies; and (e) addresses itself to the unique characteristics of the surrounding community.

For example, when considering how to provide electricity to Duchity on a 24/7 basis, we, and those living in the community, have had to incorporate this notion of appropriate technology in a very direct and specific way. Currently, 40 households share power from a $17 \mathrm{~kW}$ generator that operates only 3 hours per day. Because it is in disrepair, this generator functions at only $25 \%$ capacity. Which is more appropriate, the current generator technology which produces three hours of electricity per day_more if repaired — or a small hydroelectric project that would take advantage of the nearby Glace River to produce electricity at perhaps $30-300 \mathrm{~kW}$ ? Appropriate technology poses these questions in a dynamic way since it suggests considering which technological choice best brings about the transition out of the indigenous technology of the developing community. Which option best serves as the intermediate technological step?

Some argue that even "appropriate" technologies fall into the trap of providing only superficial "fixes" and disregard or do not sufficiently involve the community that the technology is intended to serve. Many believe that appropriate technologies are not adequately evaluated and are, therefore, prone to disuse. Finally, many believe that such technologies do not scale properly to affordability and fail to be of use to a critical mass of people. We recognize these objections but argue that appropriate technology can be conceived and implemented broadly enough to avoid these pitfalls.

Humanitarian Engineering also broadens the scope of engineering to address the needs and capabilities of developing communities. After an extended discussion of the historical shifts in 
the attitudes that engineers have taken toward humanism, Mitcham and Muñoz draw together the different strands in the following characterization of "humanitarian engineering":
[H]umanitarian engineering seeks to work within a new self-imposed constraint of seeking to help meet the basic needs of under-served populations. In brief, humanitarian engineering in the most general terms is the artful drawing on science to direct the resources of nature with active compassion to meet the basic needs of all-especially the powerless, poor, or otherwise marginalized ${ }^{2}$.

These authors, Lucena et al. ${ }^{3}$, Baillie \& Catalano ${ }^{4}$, Riley ${ }^{5}$, and others take the view that working with the marginalized and the poor does not imply charity. Rather, a true partnership with the community that is being served must be forged through a model where the community is involved in decision-making and management of projects. We understand this to be true for our broader view of appropriate technology, and note that this applies, not only to engineers or engineering projects, but to all who develop, sell, manage, and otherwise proliferate technology.

In working with Duchity, we have made efforts to avoid falling into the "charity trap". Empowering community members to take charge of their technological choice poses a much greater challenge than just identifying and fulfilling needs on the charity model. It requires setting up a "deep dialogue" with the community to gain insight into their values, knowledge, skills, and ways of life ${ }^{10}$. Appropriate technologies are plastic and adaptable; they can and should be modified to incorporate community values, knowledge, skills, and ways of life. If they conflict with or endanger these, then they should be rejected. In our initial dialogue with Duchity, we have identified a series of possible projects: (1) fixing the existing generator to increase its efficiency; (2) constructing a small scale hydroelectric facility on the Glace River; (3) developing educational modules for a local orphanage in French language, mathematics, and engineering concepts; (4) partnering on locally-directed agricultural projects; (5) identifying (or designing) clean cooking stoves for indoor cooking. Humanitarian engineering provides a broader, richer perspective from which to examine and test the appropriateness of these projects.

Capabilities. The Capabilities Approach set forth by Amaryta Sen and Martha Nussbaum provides a particularly useful way of unpacking the term "humanitarian," one that corrects the prevailing paternalistic approaches that impose needs, desires, preferences, or enjoyments on the "target" community. The Capabilities Approach changes this paradigm by replacing a view of the developing community as beset with needs and deficiencies to one that characterizes it as a repository of valuable and defining capabilities. It brings to the fore humanitarian concerns by emphasizing the shaping (and reshaping) of the surrounding socio-technical system to facilitate the exercise and expression of fundamental human capacities. According to Nussbaum, capabilities help to answer in a decidedly concrete way the question, "What is this person able to do or be?", . Along with Sen, she characterizes capabilities as " substantial freedoms,' a set of (causally interrelated) opportunities to choose and act." a The Capabilities Approach, therefore, adds depth to appropriate technology by providing criteria for choice; in a sense, a technology derives its "appropriateness" from how it resonates with basic human capabilities and more

\footnotetext{
${ }^{a}$ Nussbaum continues the passage quoted above with the following: "[T]hey are not just abilities residing inside a person but also freedoms or opportunities created by a combination of personal abilities and the political, social, and economic environment" $"$.
} 
specifically whether it serves as a "conversion factor" that transforms basic capabilities into active functionings ${ }^{12}$.

Capabilities lists vary but Nussbaum's includes the following: basic capabilities (life, bodily health, bodily integrity), cognitive capabilities (senses/imagination / thought, emotions, practical reason), social or out-reaching capabilities (affiliations, other species), and agent capabilities (play and control over one's environment). Insofar as a technology plays the role of a conversion factor that transforms a capability into a functioning, then it is - in the humanistic sense of the term-appropriate. On the other hand, insofar as it thwarts capabilities and suppresses their expression it fails the test of appropriateness. When engineers adopt a capabilities focus, they broaden the design process to include close examination of how a proposed design can either encourage or diminish the conversion or realization of key capabilities. This broadens and enriches the design process toward incorporating perspectives of social justice and human dignity.

Identifying a community's capabilities and its conversion factors is necessary to avoid the paternalism of the charity approach. We (Castro and Papadopoulos) have already made two trips to Haiti to initiate a deep dialogue with community stakeholders. Last October, we carried out a survey to get more information on how individual, family, and community forms of life would be affected by increased availability of electricity. Increased supply of and access to electricity could provide a conversion factor that would turn community capabilities into active functionings. For example, having electricity could extend social activities further in the evening because it would facilitate lighting; in this way it would convert the capability of affiliation into a real functioning. It could also provide better lighting for schools and allow students to work with electronic "gadgets" such as computers; thus, it would convert the capabilities of thought, emotion, and practical reasoning into actual and realized educational functionings. But it could also exacerbate the digital divide between those with the money to purchase technologies such as computers, digital TVs, and cell phones and those unable to do so. Schumacher's warning against moving too quickly from indigenous to highly capitalized technologies clearly applies here. Sen and Nussbaum's Capabilities Approach substantiates this caution by prompting the question of whether a 24/7 electricity accomplishes or thwarts the conversion of capabilities into functionings.

Socio-technical System. Determining whether a technology is appropriate requires close attention to the socio-technical background which forms a system, a "complex environment of interacting components, together with the networks of relationships among them" to Huff, a socio-technical system is "an intellectual tool to help us recognize patterns in the way technology is used and produced" 13 . For example, Huff has his computing students write "Social Impact Statements" to outline the impact a computing technology would have on the sociotechnical system (STS) in which it is being integrated. Students triangulate their impact claims through day-in-the-life scenarios, participatory observation, and surveys; any claim made on the impact of a technology has to be substantiated through three different methods of observation ${ }^{14}$ (in private conversations).

Socio-technical systems exhibit several important characteristics. First, a STS can be divided into components such as hardware, software, physical surroundings, people/groups/roles, 
procedures, laws/statutes/regulations, and information systems. This list of distinguishable components varies according to context and purpose. Second, these distinguishable components are, nevertheless, inseparable from one another; STSs are, first and foremost, systems. Third, a key component of both technologies and STSs is their ability to embody or embed values. By exploiting this, students can prepare Social Impact Statements that identify and locate embedded values, chart out potential conflicts, and recommend system adjustments to remediate these. STS analysis, thus, adds a dimension to the determination of the appropriateness of a given technology by raising the question of whether its incorporation leads to value conflicts. Finally, these value conflicts cause STSs to change. Because STS changes are directional, they trace out trajectories. Thus, another test of appropriate technology is whether its integration into a STS places that system on a positive or negative trajectory of change.

Turning to Duchity, the appropriateness of the hydro-electric project depends on how the values embodied in this project-say, productivity, efficiency, and environmental integrity since the hydroelectricity project uses renewable resources - resonate with other values in the broader STS such as justice and solidarity. Could the widespread availability of electricity increase the gap between those with the financial resources to purchase electricity-consuming devices and those who lack this ability? Would this increase in the "technological divide" lead to a diminishing of community solidarity and the marginalization of key community groups? Our appropriate technology framework (humanitarian engineering, capabilities approach, and social impact analysis) allows us to pose these normative questions, and, at the same time, suggests lines of empirical research (participatory observation, day-in-the-life scenarios, and surveys/interviews) to answer them.

These concepts raise normative questions about appropriate technology projects in developing communities. But more to the point, they suggest lines of empirical inquiry that bring about actionable answers. In the next two sections we look at how appropriate technology changes the use and meaning of basic concepts in research ethics and then summarize the results of a survey carried out in Duchity, Haiti October 2011 on electricity use.

\section{Two Research Ethics Issues Raised by Appropriate Technology}

Traditional research ethics poses issues that overlap with community development and appropriate technology. But can research concepts be directly transferred from theoretical science to appropriate technology without changes, adaptations, or modifications? How do these areas overlap — and then differ - in terms of the ethical challenges they pose to practitioners? This section explores two traditional challenges in research ethics, paternalism and informed consent. It will show how placing them in the context of community development and appropriate technology expands their meaning and import. Our concerns in the interaction with Duchity lie in avoiding paternalism by working hard to gain community participation in any appropriate technology project and by identifying a valid procedure for documenting informed consent.

Paternalism. Sander Lee in the Encyclopedic Dictionary of Business Ethics defines paternalism as "[a]n activity undertaken by one party (e.g., an individual, organization, or government) for the supposed "good" of a second party without the consent of the second party or in direct 
violation of the second party's stated wishes"14. Avoiding paternalism adds an important dimension to the role an engineer should play when volunteering expertise and skill to a developing community. It also expands the pedagogical agenda for training engineers by targeting skills such as moral creativity and moral imagination.

For example, paternalism may be triggered, not so much by a community's actual needs and disadvantages, but by a vision on the part of the engineer that lacks moral imagination. Here, an engineer would view a community as deficient and needy in relation to unquestioned and unexamined standards of standards of progress and technological "appropriateness." Moral imagination would require stepping back from the standpoint of unquestioned technological superiority to re-imagine the community as a repository of capabilities, skills and resources. ${ }^{b}$

Re-imagined in this way, technological projects and designs become conversion factors that convert community capabilities into realized functionings. Designing new technologies as conversion factors aligns them with community capabilities, empowers the community of users by bringing them into the design process, and strategically avoids the dystopia of reverse adaptation described by Winner where a community's goals and aspirations are subordinated to the goals of autonomous, out-of-control technologies. ${ }^{c}$ To avoid paternalism in our partnership with Haiti, we have initiated a series of dialogues with community stakeholders, worked with brokering organizations such as Youthhaiti to understand community capabilities, and immersed ourselves in community social networks. Our survey recently translated into Creole and administered to 199 community members has helped us to form a richer picture of the community's concrete repository of capabilities.

Informed Consent. Traditionally engineers are responsible for exercising care and foresight to prevent or minimize untoward results stemming from engineering practice. But they are also responsible for making sure clients and members of the general public understand and consent to the risks associated with engineering projects.

Appropriate technology and community development further expand the meaning of informed consent (as well as attendant engineering responsibilities) by requiring, not just the consent of community stakeholders, but their active participation. Now engineers must also engage community participation in the formulation and implementation of technological projects; the community members should become partners-in-design. This requires striving toward technological designs that are responsive to both basic human capabilities in general, and the form that these capabilities take in individual communities. Engineers must work with communities to incorporate into designs their cultural, social, historical, and political substance. Consent in community development, therefore, follows from participation in the design process.

\footnotetext{
${ }^{\mathrm{b}}$ Werhane defines moral imagination as "a necessary ingredient of responsible moral judgment [that entails]...the ability to discover, evaluate and act upon possibilities not merely determined by a particular circumstance, or limited by a set of operating mental models, or merely framed by a set of rules or rule-governed concerns."15

${ }^{c}$ According to Winner, "[T]echnical systems, once built and operating, do not respond positively to human guidance. The goals, purposes, needs, and decisions that are supposed to determine what technologies do are in important instances no longer the true source of their direction. Technical systems become severed from the ends originally set for them and, in effect, reprogram themselves and their environments to suit the social conditions of their own operations."
} 
This stands in sharp opposition to the traditional model where consent is tacked on after the engineer explains the risks associated with already accomplished designs.

While the notion of informed consent might originate from an ethical standpoint, it also has the practical value of building trust ${ }^{16}$. As a result, paternalistic choices will be avoided, and better overall technical solutions will be deployed and maintained.

This participatory process of developing appropriate technology will often require the engineer to communicate directly with community members through public meetings, surveys, and interviews. Aside from practical issues such as needing a translator, this process can potentially require methods that would violate the strict norms of the engineer's native society. For example, it does not make sense to offer an "informed consent form" requiring a signature to an illiterate respondent. Likewise, strict conventions to ensure privacy might not make sense in a community where family members are consulted on important decisions or where decisionmaking habitually takes on a collective form ${ }^{17}$.

Consequently, insistence on strict standards of informed consent that are not appropriate to the community can have an alienating effect, which is, of course, contrary to the spirit of informed consent in the first place. In general, the engineer must be prepared to exercise good judgment, perhaps akin to what a conscientious journalist does in the field. For example, verbal discussion of the respondent's right to refuse an interview can be carried out by those sensitive to the respondent's surrounding socio-technical system.

\section{Application to Project in Duchity, Haiti}

This article stems from an ongoing project entitled "Graduate Research and Education for Appropriate Technology: Inspiring Direct Engagement and Agency (GREAT IDEA), which is sponsored by the NSF Ethics Education in Science and Engineering (EESE) Program

(\#1033028). GREAT IDEA has been partnering with the community of Duchity, Haiti, located in the mountains of Haiti's southwestern peninsula. The decision to work in Duchity was based on extending an existing contact with a US NGO called Youthaiti, whose mission is to foster health, sanitation, and agricultural development. Two of the authors visited Duchity for the first time in March 2011; one returned for a subsequent visit in October 2011, and the other will return in March 2012.

In keeping with the appropriate technology framework outlined previously, we went with in an open mind regarding what our role and contribution should be. We arranged to meet with a local leadership group, including the mayor and other members of the Duchity Electric Committee, which manages the village's small 17kW generator that serves 40 houses for 3-4 hours per night. Although we did assume that electrical power generation was the village's most pressing need, many members of this group were clear that they would like to increase the capacity of the system to provide electricity $24 / 7$.

This has begun a process of deep dialogue ${ }^{10}$. We certainly have the utmost respect for the group's expression of this desire, and considering our own unlimited access to electricity in our home culture, it is difficult not to want to advance this opportunity to others. The first two visits 
allocated much time to investigating where to locate a small hydroelectric generator by mapping elevations in a local river with GPS. Two partnerships have emerged from this work, one with a US engineer and another with a Haitian national currently working in the US as an engineer.

However, we understand that our role in this process involves more than just providing technical assistance and that we should be open to the possibility that the system should not even be built because of risks possibly hidden in the socio-technical system. Indeed, we have already discovered some potential environmental obstacles, such as the flooding of the river basin during the rainy season that might interfere with constructing a sustainable hydroelectric generator. Therefore, we must, not only consider the feasibility of a hydroelectric plant, but also evaluate alternative means to generate power.

More broadly, we believe that additional aspects of any project's impacts must be thoroughly investigated and openly discussed. Our role here is to facilitate the community's own philosophy of technology conversation giving rise to, among other outcomes, informed consent and active participation.

To this end, we developed a survey that was translated into Haitian Creole and disseminated to 199 people in Duchity in October 2011. The timing of the survey coincided with a health clinic that was sponsored by our partner Youthaiti, and, therefore, we were able to survey a number of people who had travelled in from the surrounding regions.

The questions of the survey (26 questions) were developed in consultation with an engineer along with a Haitian student at our campus. The survey was designed to ask broad questions regarding overall quality of life issues and gradually focus on questions about development, energy alternatives and uses, and the need of and desire for electrical power. The survey was translated and delivered in Haitian Creole and then translated back into English by the Haitian student at our campus. Two members of the Duchity Electric Committee were trained to give the survey orally and to record the results on paper. However, many of the surveys were distributed directly to the literate respondents who wrote out their answers. This, perhaps, had the effect of decreasing the specificity of many of the answers because the interviewer was not present to probe the respondents for more detail. A total of 199 survey responses were collected. To date, 111 of 199 surveys have been translated and tabulated; in many cases, open responses have been manually coded. A detailed excerpt of the survey questions and results appears in the Appendix.

Before summarizing the results of the survey, we note two emergent shortcomings in its design. First, after the survey was printed (250 copies), some members of the Electric Committee suggested revisions; we decided not to incorporate these because they would have required manual correction and also would have pushed pending time deadlines. Second, based on one of these suggested revisions, which was to rephrase the first question in terms of life 'satisfaction' rather than 'happiness', we realized that the new economics foundation itself, which has motivated our use of happiness indices, has a standard set of questions that also uses the word 'satisfaction' rather than 'happiness'. In future iterations, we will elicit more community feedback and include other existing surveys as a baseline. 
With this in mind, the survey revealed the following:

- Consistent with the original message from the Electric Committee in March 2011, electricity is a highly desired technology to have, and it was the highest ranking response to the question "what types of development would you like to see in Duchity ..." (Q4). However, in the prior question "what would you like to improve in your life" (Q3), electricity was a very low ranking response.

- When asked "Are you worried about any of the following possible negative effects of an electricity system?" (Q12), the only concern that was raised with some frequency was the possibility of "Eliminating use of certain areas of the river". A strikingly large number of respondents volunteered an answer that was not given from the choice list: that there would not be any negative consequences.

As part of the visit of March 2012, a follow up discussion will be held with members of the local community to gain further insight into these and other responses. We have some concerns that the responses to Q12 indicate either a lack of awareness or a lack of concern regarding some negative consequences of an electrical power system, and in the context of the "deep dialogue" that we intend, we will seek further comment on this matter. Although the discussion of such consequences is intended to foster informed consent, it might also be tainted with our own paternalistic attitudes that presume that people must understand certain outcomes as we do. Indeed, it is both awkward and questionable for individuals such as ourselves, who have essentially unlimited access to electricity and many other life comforts, to insist that the people of Duchity focus intently on negative consequences. Yet, by the same token, would it be responsible for us to neglect this conversation when perhaps a deeper dialogue might reveal more deeply held attitudes and ultimately lead to a sounder project?

A way forward here is to return to the Capabilities Approach. In April 2011, when we gave a summary of our first visit to a selected audience of colleagues and other interested individuals at UPRM, a native Haitian and a faculty colleague both expressed the importance of linking the development of electrical power to supporting businesses and industries that could be used to grow the local economy. It was these comments that motivated Q4 and Q10.

The survey data is inconclusive on how electric power will assist these people in their occupations. (Only general answers were provided to Q10.) The responses to these and other questions did not provide a clear answer to how the community views electricity as useful for supporting a specific type of development; in fact, Q4 suggests that electricity itself is considered a development end. In hindsight, the survey did not elicit such specific responses, and further questions will likely reveal links between the community's capabilities and its collective desire to have electricity. The survey did reveal that a significant number of the respondents are farmers or merchants (Q17). We will explore in the future how these occupations could make use of electric power.

\section{Pedagogical Implications: Toward Alternative Career Paths for Engineering Students}

Downey and Lucena ${ }^{18}$ discuss alternative career paths open to engineers based on expanding the decision-making perspective to include the role engineers play in an interdisciplinary process of 
problem definition. This has led them to reformulate available career paths that should be addressed in engineering education. Traditionally, engineering students choose between different, highly specialized branches such as civil, mechanical, chemical, electrical, industrial, and materials science. The engineer develops highly specialized knowledge and skill in a particular branch or specialty. Then he or she finds a job in an organization where decisionmakers have repeated uses for such technical knowledge and skill offered in an advisory capacity. On this model, engineers have no general role in the formulation and resolution of broader, everyday problems; instead, they receive ready-made problems from supervisors and provide technical information pertinent to their resolution.

Downey and Lucena argue that engineers should play a broader role in problem-solving and decision-making. They identify several different career tracks and hold that the engineering curriculum should be redesigned to develop skills appropriate to excelling in these new career options. They propose a research track to help students prepare for research positions in private industry or graduate school. In addition, they identify tracks in design, engineering and management, and engineering and society. These would ground students in the fundamentals of engineering but then prepare them for bringing their knowledge to bear in situations that pose moral, social, global and political as well as technical problems.

In particular, the framework of Downey and Lucena can be applied to make students aware that engineers can find meaningful work that focuses on community development projects, and that a knowledge base exists that can provide them with appropriate training. Of course, we don't expect that all students will take careers that explicitly operate in developing countries, but some lessons of development engineering practice can still inform student decisions in even conventional situations. We can explore this in three contexts.

1. Engineers could work within multinational corporations (MNC) in both preventive and proactive capacities. From the prevention standpoint, they can serve as a kind of corporate conscience and work to help the company avoid exercising paternalism toward developing communities and to help them identify moral risks associated with working in corrupt or unstable environments ${ }^{19}$. From a proactive standpoint, engineers with training in community development could help realign company corporate social responsibility programs. Frequently, CSR programs have served little more than to give the company good publicity; their positive impacts have been limited and they have rarely elicited community participation in design and implementation. But Werhane et al. ${ }^{10}$ point to a few companies that have reconfigured CSR to forge meaningful partnerships with communities. These MNCs have cultivated the skills of deep dialogue to understand community capabilities and have designed CSR initiatives (partnering with the communities) that connect to core corporate values and competencies. Engineers with experience in community development can play a critical role in this reconfiguring of MNC corporate social responsibility.

2. Engineers working with organizations such as Engineers Without Boarders have also established a tradition of working with NGOs (non-government organizations) in various capacities. The case of the Uchangi dam (which the authors use in a module on technology choice) shows this role clearly ${ }^{20}$. Here, engineers played a crucial, brokering role by mapping out a community's capabilities and then building them into a counter-design for a smaller scale 
irrigation project that delivers on the government's goals for its larger-scale project but also mitigates the harmful impact of such a large project on small, marginalized communities. To be effective in this career path, an engineer would have to be skillful in translating community capacities and values into appropriate technology designs; they would have to be both cultural anthropologists and technically proficient engineers.

3. Social Entrepreneurship is a loosely organized movement based on deploying the methods of entrepreneurship to solve difficult social problems ${ }^{21}$. The pedagogical agenda for an engineering track in this area would include traditional engineering teaching but then expand into the socalled "soft" skills outlined by Werhane et al. ${ }^{10}$ : (a) moral imagination (reframing needs and disadvantages into opportunities and capabilities), (b) systemic thinking (to see how technologies integrate into broader social-technical contexts), and (c) "deep dialogue" where engineers and community members treat one another as equals and partners in a conversation designed to build community capacities into business ventures and appropriate technologies ${ }^{10}$. Engineers trained in soft as well as hard skills could play a major role in expanding both the range and impact of social entrepreneurship efforts.

\section{Conclusion}

This paper began by describing a movement in engineering geared to addressing problems in developing countries. By drawing a map of interrelated concepts (appropriate technology, humanitarian engineering, Capabilities Approach, and Socio-Technical Systems) it has created a broad-based framework for understanding this new engineering role. And, as a new mode of research, it has led to the reinterpretation and incorporation of research ethics concepts like paternalism and informed consent. This framework and its new approach to research ethics has helped us to understand better the partnership our project is developing with the community of Duchity, Haiti.

We ended with a brief description of the pedagogical agenda our approach lays bare. By incorporating the so-called soft skills of moral imagination, systemic thinking, and deep dialogue into more traditional engineering educational approaches, it empowers engineers to work effectively on socially and globally enriching projects. Engineers trained from this broader perspective can serve as agents of change that place Multi National Corporations on positive, moral trajectories of change, sustain powerful initiatives like Engineers Without Boarders, and inform Social Entrepreneurship projects geared toward solving interdisciplinary social and global problems.

\section{Bibliography}

${ }^{1}$ Vesilind, A. Peace Engineering: When Personal Values and Engineering Careers Converge, Pakeshore Press, 2005.

${ }^{2}$ Mitcham, C. and D. Muñoz. Humanitarian Engineering, Morgan \& Claypool, 2010: 35. 
${ }^{3}$ Lucena, J., J. Schneider, and J.A. Leydens. Engineering and Sustainable Community Development, Morgan \& Claypool, 2010.

${ }^{4}$ Baillie, C. and G. Catalano. Engineering and Society: Working Towards Social Justice, Parts IIII, Morgan \& Claypool, 2009.

${ }^{5}$ Riley, D. Engineering and Social Justice, Morgan \& Claypool, 2008.

${ }^{6}$ Easterly, W. The White Man's Burden: Why the West's Efforts to Aid the Rest Have done so Much Ill and so Little Good. New York, The Penguin Press, 2006.

${ }^{7}$ Schumacher, E. F. Small Is Beautiful: Economics as if People Mattered, Harper Prennial, 1973/2010: 188-201.

${ }^{8}$ Supplemental definition of appropriate technology found at Portal: Appropriate Technology. http://www.appropedia.org/Portal:Appropriate_technology.

${ }^{9}$ Winner, L. Autonomous Technology: Technics-out-of-Control as a Theme in Political Thought. MIT Press, 1978: 227.

${ }^{10}$ Werhane, P., S.P. Kelley, L.P. Hartmen, D.J. Moberg. Allievating Poverty through Profitable Partnerships: Globalization, Markets and Economic Well-Being, Routledge, 2010: 21, 26-7, 75$85,91$.

${ }^{11}$ Nussbaum, Martha C. Creating Capabilities: The Human Development Approach, Belknap Press of Harvard University Press, 2011: 20, 33-34.

${ }^{12}$ Robeyns, Ingrid, "The Capability Approach", The Stanford Encyclopedia of Philosophy (Summer 2011 Edition), Edward N. Zalta (ed.), URL = <http://plato.stanford.edu/archives/sum2011/entries/capability-approach/>. Accessed March 12, 2012.

${ }^{13}$ Huff, C. "What is a Socio-Technical System?" From Computing Cases website. http://computingcases.org/general_tools/sia/socio_tech_system.html. Accessed January 10, 2012.

${ }^{14}$ Lee, Sander. "Paternalism." In Werhane, P, and R.E. Freeman (Eds.) Blackwell Encyclopedic Dictionary of Business Ethic,. Blackwell, 1997: 480-481.

${ }^{15}$ Werhane, P. Moral Imagination and Management Decision-Making, Oxford University Press, 1999: 93.

${ }^{16}$ M. Jablonski, C. Papadopoulos, and J. Reisel. "Building Trust in International Development Work: A Case Study of a Recent EWB Project". Proceedings of the ASEE Annual Conference and Exposition, Austin, TX, June 2009. 
${ }^{17}$ Schrag, B. "Research with Groups: Group Rights, Group Consent, and Collaborative Research: Commentary on Protecting the Navajo People through tribal regulation of research", Science and Engineering Ethics (2006) 12(3): 511-521.

${ }^{18}$ Downey, Gary \& Juan Lucena. "Are Globalization, Diversity, and Leadership Variations of the Same Problem?: Moving Problem Definition to the Core." Distinguished Lecture to the American Society for Engineering Education, Chicago, Illinois 2006.

${ }^{19}$ Phadke, R. "People's Science in Action: The Politics of Protest and Knowledge Brokering in India" (1987). In Johnson, D.G. and Wetmore, J.M. (Eds.). Technology and Society: Building Our Sociotechnical Future, MIT Press, 2009: 499-513.

${ }^{20}$ Werhane, P., R. Velamuri, D.E. Boyd. "Corruption and moral risk in business settings," In Kirk Hanson (Ed.) The Responsible Corporation, Greenwood Publishers, 2006: 235-258.

${ }^{21}$ Colby, A, Ehrlich, T., Sullivan, W. \& Dolle, J. Rethinking Undergraduate Business Education: Liberal Learning for the Profession. Carnegie Foundation, 2011: 142. 


\section{Appendix. Summary of Attitudes Survey in Duchity, October 2011}

A survey was distributed to 199 people in Duchity in October 2011. To date, responses of 111 respondents have been translated and compiled. Questions were of two types: (1) closed form questions in which the respondent chooses one or more items from a prepared list, and (2) open form questions in which the respondent expresses any view(s), and for which the results are then manually coded for tabulation purposes.

Each response was counted once for each question, i.e., in cases that permit multiple responses, each response is counted as a separate response. For example, in Question 5, many respondents indicated using more than one form of energy. In principle, all open form questions are potentially multiple response type questions, but in practice some open form questions are coded as single response, as indicated. This explains why $\mathrm{N}=425$, greatly exceeding the number of respondents (111).

In the tables below, the types and tabulation methods are identified for each question.

1. Thinking of your overall quality of life, to what degree do you feel that you and your family lead a happy life? ( $N=107$, closed form, single response)
a. Very happy
b. Somewhat happy
$56(52.3 \%)$
$20(18.7 \%)$
c. Somewhat unhappy
$10(9.3 \%)$
d. Very unhappy
$21(19.6 \%)$

2. What do you like about your life now? ( $N=76$, open form, manually coded, single response)
a. Did not directly answer, but indicated some desire to change
$38(44.7 \%)$
b. Provided a negative response, for example "nothing"
$29(38.2 \%)$
c. Provided a positive response, for example, good health
$13(17.1 \%)$

\begin{tabular}{|c|c|}
\hline 3. What would you like to improve in your life? (N=114, open form, manually coded, multiple responses) \\
\hline a. Provided a general response, such as "everything" & $37(43.5 \%)$ \\
b. Provided a general response related to "development" & $10(11.8 \%)$ \\
c. Indicated desire to have more money, jobs, better economy & $25(29.4 \%)$ \\
d. Indicated desire to have better hospitals & $13(15.3 \%)$ \\
e. Indicated desire to have better education & $15(17.6 \%)$ \\
f. Indicated desire to have better infrastructure (electricity, roads, housing, etc.) & $14(16.5 \%)$ \\
\hline
\end{tabular}

\begin{tabular}{|c|c|}
\hline \multicolumn{2}{|c|}{$\begin{array}{l}\text { 4. What type of progress would you like to see in Duchity and the surrounding area? ( } N=188 \text {, open form, } \\
\text { manually coded, multiple responses) }\end{array}$} \\
\hline a. General aspiration for development or progress & $34(18.1 \%)$ \\
\hline b. Improved jobs, employment, or business opportunities & $4(2.1 \%)$ \\
\hline c. Improved hospitals and healthcare & $35(18.6 \%)$ \\
\hline d. Improved education and schools & $31(16.5 \%)$ \\
\hline e. Improved roads and public spaces & $17(9.0 \%)$ \\
\hline f. Improved food and agriculture & $6(3.2 \%)$ \\
\hline g. Improved electricity & $38(20.2 \%)$ \\
\hline h. Improved water \& sanitation facilities & $12(6.4 \%)$ \\
\hline i. Improved political and economic systems & $11(5.9 \%)$ \\
\hline
\end{tabular}




\begin{tabular}{|c|c|}
\hline 5. What current sources of energy do you use? ( $\mathrm{N}=425$, closed form, multiple responses) \\
\hline a. Burning wood & $104(24.5 \%)$ \\
b. Charcoal & $89(20.9 \%)$ \\
c. Gasoline & $18(4.2 \%)$ \\
d. Kerosene & $61(14.4 \%)$ \\
e. Electricity & $70(16.5 \%)$ \\
f. Battery & $76(17.9 \%)$ \\
g. Other & $7(1.6 \%)$ \\
\hline
\end{tabular}

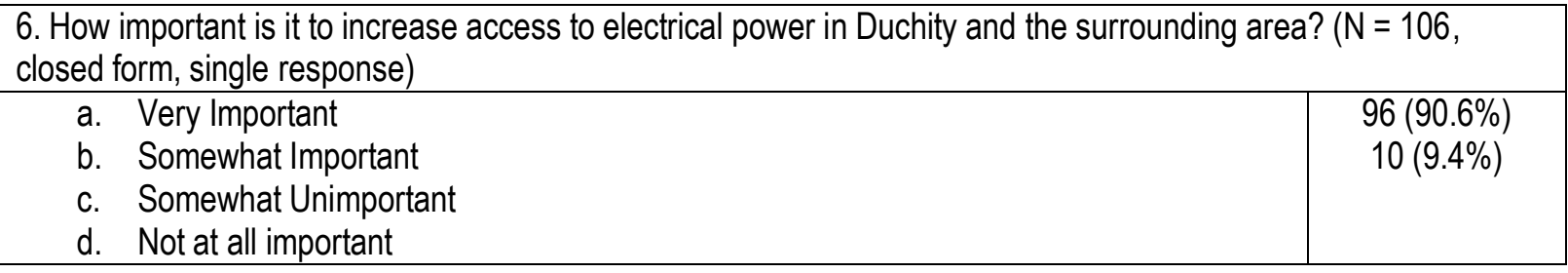

\begin{tabular}{|c|c|}
\hline 7. Have you ever had access to electricity in your home? ( $N=110$, closed form, single response) \\
\hline a. Yes & $25(22.7 \%)$ \\
b. No & $85(77.3 \%)$ \\
\hline
\end{tabular}

\begin{tabular}{|c|c|}
\hline 8. If you had access to electricity in your home, do you feel it would improve your quality of life? ( $\mathrm{N}=104$, closed \\
form, single response) \\
\hline a. Yes & $103(99.0 \%)$ \\
b. No & $1(1.0 \%)$ \\
\hline
\end{tabular}

9. How would you use electrical power if available in your home? ( $N=116$, open form, manually coded, multiple responses)
a. Indicated a generally positive response, but did not provide specific use
b. Indicated the need to be careful (e.g. to avoid shock)
c. Indicated that electricity use would be directed by someone else
$50(43.1 \%)$
$9(7.8 \%)$
d. To increase or provide jobs, employment, economic growth
$25(21.6 \%)$
e. Lights
f. Appliances (TV, radio, phones)
$12(10.3 \%)$
g. Substitute for gasoline
$9(7.8 \%)$
$5(4.3 \%)$
$1(0.9 \%)$
h. Other
$5(4.3 \%)$

10. How would having reliable electricity available help you in your occupation? $(N=92$, open form, manually coded, multiple responses)
a. Indicated a generally positive response, but did not provide specific detail
b. Indicated a generally positive response specifically related to work, but did not provide further detail
c. Indicated the ability to make more money
d. Indicated the possibility of creating new jobs
$34(40.0 \%)$
$18(19.6 \%)$
e. Unemployed/not relevant 
11. Do you think having reliable electricity in Duchity would be good for the community? If so, why? ( $N=95$, open form, manually coded, multiple responses)
a. Yes, but did not provide specific detail
$24(25.3 \%)$
b. Yes, and related to development or progress
$47(49.5 \%)$
c. Yes, to increase the ability to make more money
d. Yes, to increase general wellbeing or quality of life

12. Are you worried about any of the following possible negative effects of an electricity system? $(\mathrm{N}=88$, closed form (a)-(e), open form (f), (f) manually coded, multiple responses)
a. Eliminating use of certain areas of the river
$20(22.7 \%)$
b. Disturbing wildlife
$0(0.0 \%)$
c. Running cables through people's property
$4(4.5 \%)$
d. Large outside or foreign company running the business and setting the price
e. Causing flooding (large hydroelectric)
$2(2.3 \%)$
$0(0.0 \%)$
f. Other - mostly indicated that there were no problems
$62(70.5 \%)$

13. Would you be willing to pay a monthly fee to maintain the electrical system in the village? If so, how much? ( $N=94$, open form, manually coded, single response)
a. Yes, but did not provide specific detail
$50(53.2 \%)$
b. Yes, and specified US $\$ 20-$ US $\$ 40$
c. Yes, and specified G50 - G200 (equivalent to $\$ 1.25-\$ 5$ )
$11(11.7 \%)$
$12(12.8 \%)$
d. Yes, and specified whatever is required
e. No, nothing
$20(21.3 \%)$
$1(1.1 \%)$

17. What is your occupation? (N=109, open response, manually coded, single response)
\begin{tabular}{l|c} 
a. Small business/merchant & $34(31.2 \%)$ \\
b. Student/school & $5(4.6 \%)$ \\
c. Gardening, farming, agriculture & $55(50.5 \%)$ \\
d. Miscellaneous (taxi driver, teacher, doctor, carpenter) & $6(5.5 \%)$ \\
e. Not working & $9(8.3 \%)$ \\
\hline
\end{tabular}

Bibliography:

1 -Vesilind, 2005 